\title{
How long should Atrovent be given in acute asthma?
}

\author{
C Brophy, B Ahmed, S Bayston, A Arnold, D McGivern, M Greenstone
}

\begin{abstract}
Background-In acute asthma the optimal duration of treatment with combination $\beta$ agonist and anticholinergic nebuliser solutions is unknown; most studies have investigated single doses or treatment for up to 12 hours. To determine whether longer treatment with ipratropium bromide might aid recovery a study was undertaken in 106 patients with acute asthma.
\end{abstract}

Methods-A double blind, randomised, placebo controlled, three group study was performed with all patients receiving ipratropium for 12 hours and salbutamol for 60 hours after admission (both nebulised four hourly), systemic steroids and, if necessary, theophylline. At 12 hours ipratropium was stopped in group $I$ ( $n=$ 35) but was continued in the other two groups, and at 36 hours ipratropium was also stopped in group II $(n=35)$ while patients in group III $(n=36)$ continued with ipratropium for 60 hours. Spirometric tests were performed before and after salbutamol, and again 30 and 60 minutes after ipratropium or placebo at 12,36 and 60 hours. Peak flow rates (PEFR) were measured before and after each nebulisation.

Results-There were no differences between the groups in PEFR on admission (group I: $214 \mathrm{l} / \mathrm{min}$, group II: $198 \mathrm{l} / \mathrm{min}$, group III: $221 \mathrm{1} / \mathrm{min}$ ), or mean forced expiratory volume in one second $\left(\mathrm{FEV}_{1}\right)$ at 12 hours (group I: 1.81 , group II: 2.01 , group III: 2.21 ), 36 hours (group I: 2.11 , group II: 2.31 , group III: 2.41 ), or at 60 hours (group I: 2.2 1, group II: 2.3 1, group III 2.5 1). Despite this, median time to discharge was significantly higher for patients in group I (5.4 days) than for those in groups II (4.1 days) and III (4.0 days). Conclusions-Combination nebulised therapy can be continued beyond 12 hours and up to 36 hours after admission with improved recovery time. Lung function testing may not reflect the full benefit of treatment.

(Thorax 1998;53:363-367)

Keywords: ipratropium bromide; acute asthma

Current recommendations regarding the treatment of an acute severe attack of asthma advocate short term use of nebulised salbutamol, with or without the addition of ipratropium bromide. ${ }^{1}$ The data on the efficacy of added ipratropium bromide are equivocal, but the majority of papers describe a benefit. Compared with single therapy, the combination of a $\beta$ agonist and an anticholinergic may increase the maximal bronchodilatation, ${ }^{2-6}$ increase the duration, ${ }^{7}$ or the rate of bronchodilatation. ${ }^{8}$ However, most work has investigated only single doses or dosing over a few hours. Only one study involved administration for more than 24 hours, ${ }^{3}$ and the optimal duration of treatment with ipratropium bromide is not known.

Recent work has shown that, as the baseline peak flow rate improves in the days following an acute attack of asthma, the proportion of bronchodilatation provided by ipratropium bromide relative to the $\beta$ agonist terbutaline increases. ${ }^{9}$ This might suggest that ipratropium bromide provides a specific and increasing benefit, and that use should be continued rather than stopped early. The aim of this study was to ascertain whether continued administration of ipratropium bromide beyond the first few hours after admission to hospital would aid recovery and, if so, to determine the optimal duration of treatment.

\section{Methods}

SUBJECTS

All patients admitted to hospital with an acute attack of asthma were deemed eligible for entry. Those found subsequently, from notes or on observation during the admission, to have chronic obstructive pulmonary disease, defined as $<15 \%$ variability in peak expiratory flow rate (PEFR) with treatment or from night to morning, were excluded from the study. The study was approved by the local ethics committee and all patients gave their informed consent.

\section{STUDY DESIGN}

The study was a double blind, placebo controlled, three group comparison. Following admission, all patients were prescribed $5 \mathrm{mg}$ nebulised salbutamol and $500 \mu \mathrm{g}$ nebulised ipratropium every four hours. The requirement for nebulised treatment during the night was judged in each individual case. Nebuliser solutions were isotonic and preservative-free, and made up to $4 \mathrm{ml}$ with the addition of normal saline. Salbutamol was administered first, followed by ipratropium, and ipratropium was administered only after the measurements of response to salbutamol had been made.

On entry to the study patients were randomised double blind to one of three groups. The same regimen of salbutamol and ipratropium was administered to all patients for a period of 12 hours from the time of admission (0-12 hours (period 1); fig 1). After this, patients in group I were changed to salbutamol 


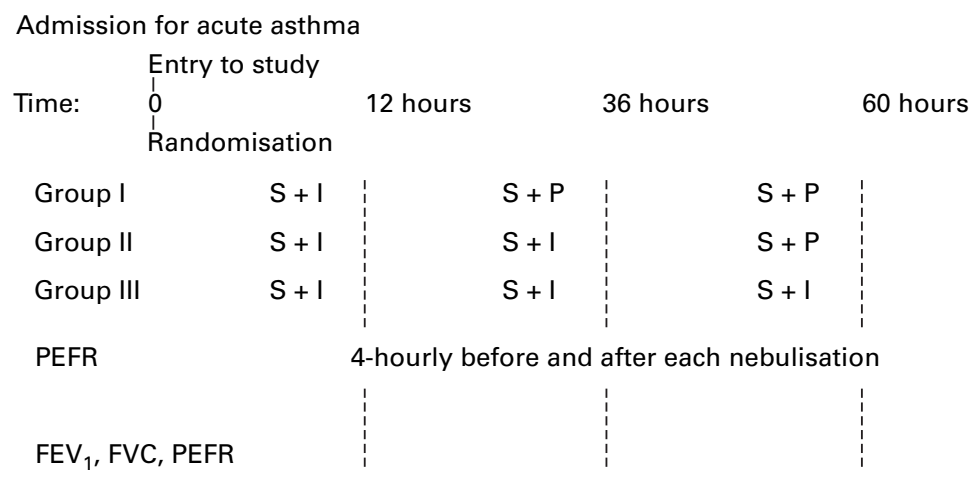

20 minutes after salbutamol,

30 minutes after ipratropium/placebo

60 minutes after ipratropium/placebo

Symptom scores - on each day of the study, at the same time of day

$\mathrm{S}=$ salbutamol

$\mathrm{I}=$ ipratropium bromide

$\mathrm{P}=$ placebo

Figure 1 Study plan. $P E F R=$ peak expiratory flow rate. $F E V_{1}=$ forced expiratory volume in one second; $F V C=$ forced vital capacity.

followed by placebo (normal saline) for the remaining 48 hours of the study. Patients in group II continued to receive salbutamol and ipratropium for a further 24 hours (12-36 hours (period 2)) and thereafter were changed to nebulised salbutamol and placebo, which they received for the remaining 24 hours of the study (36-60 hours (period 3)). Patients in group III received nebulised salbutamol and ipratropium for the entire 60 hour period. The randomisation was not stratified by the admitting consultant because the treatment and discharge policies of the consultants were similar.

The decision about transferring a patient from high dose nebulised bronchodilator to standard dose therapy was based on the clinical state of that individual. Those patients who required longer treatment with nebulised bronchodilators could continue with salbutamol, with or without ipratropium, and any patients who were judged to have improved sufficiently could be transferred to metered dose inhaler or dry powder device within 60 hours from entry.

In all other respects treatment was in accordance with that recommended in current

Table 1 Demographic characteristics of the treatment groups

\begin{tabular}{llllll}
\hline Group & $\begin{array}{l}\text { Number } \\
\text { entered } \\
\text { (male) }\end{array}$ & $\begin{array}{l}\text { Mean (SD) age } \\
\text { (years) }\end{array}$ & $\begin{array}{l}\text { Mean (SD) } \\
\text { baseline symptom } \\
\text { score }\end{array}$ & $\begin{array}{l}\text { Mean (SDits) } \\
\text { entry PEFR } \\
\text { (l/min) }\end{array}$ & $\begin{array}{l}\text { Mean (SD) diurnal } \\
\text { variability on entry } \\
(\%)^{\star}\end{array}$ \\
\hline I & $35(11)$ & $33(15)$ & $16(12)$ & $214(106)$ & $29.4(19.1)$ \\
II & $35(14)$ & $29(20)$ & $14(11)$ & $198(97)$ & $19.8(13.3)$ \\
III & $36(13)$ & $32(15)$ & $12(10)$ & $221(105)$ & $29.1(17.3)$ \\
\hline
\end{tabular}

\#Symptom score: $0=$ worst, $50=$ best.

${ }^{\star}$ Group I vs Group II, p=0.017; Group II vs Group III, p=0.014.

Table 2 Details of additional treatments during the hospital admission

\begin{tabular}{llll}
\hline & Group I & Group II & Group III \\
\hline Intravenous hydrocortisone $^{\star}$ & 8 & 12 & 7 \\
Intravenous aminophylline $^{\star}$ & 7 & 5 & 5 \\
Antibiotics $^{\star}$ & 13 & 16 & 20 \\
No. with longer than specified nebulised treatment & 12 & 13 & 15 \\
Mean (SD) duration of nebulised treatment (h) & $18.6(20.7)$ & $41.9(11.5)$ & $65.4(21.3)$ \\
$\quad$ Ipratropium bromide & $78.0(34.9)$ & $70.6(26.1)$ & $67.5(22.6)$ \\
$\quad$ Salbutamol & & & \\
\hline
\end{tabular}

^Numbers of individuals receiving each treatment. guidelines. ${ }^{1}$ All patients received oral prednisolone and, depending on the clinical state and previous therapy, patients were given high concentration oxygen, intravenous hydrocortisone, intravenous or oral theophyllines, other long acting bronchodilators, and antibiotics.

\section{MEASUREMENTS}

At 12,36 , and 60 hours PEFR was measured and spirometric tests were performed, before and 20 minutes after salbutamol and again 30 and 60 minutes after ipratropium or placebo. In addition, PEFR measurements were made before and 10 minutes after each salbutamol dose and again 15 minutes after completing each ipratropium or placebo nebulisation. Arterial blood gas tensions were measured on admission and as necessary thereafter.

On each day of the study patients were asked to grade five symptoms on a visual analogue scale of $0-10$. The symptoms graded were cough, chest tightness, shortness of breath, early morning wheeziness, and general well being. Patients were asked to score their symptoms without reference to the previous day's score.

The time to discharge was taken as the interval from admission until discharge from the ward. The decision about discharging a patient was made purely by the clinical team who cared for the patient, and who were blind to the treatment regimen received.

\section{Primary efficacy variables}

The primary efficacy variables were the change in forced expiratory volume in one second $\left(\mathrm{FEV}_{1}\right)$ during the course of the study, and the duration of hospital stay.

\section{Secondary efficacy variables}

Secondary end points were the PEFR values measured throughout each treatment period, PEFR and forced vital capacity (FVC) at the end of each period, and symptom scores. The time to reach maximum PEFR, and maximum and discharge PEFR were also compared between groups.

\section{SAMPLE SIZE}

The calculation of sample size was based on an $80 \%$ chance of detecting a clinically relevant difference in $\mathrm{FEV}_{1}$ of $300 \mathrm{ml}$. A total of 96 patients, 32 in each group, were required. Patients who withdrew before the end of the second treatment period were replaced.

\section{STATISTICAL ANALYSIS}

The efficacy of ipratropium relative to placebo was assessed by direct comparison of the three treatment groups. Analysis was based on the intention to treat. Changes in absolute spirometric and PEFR values were analysed, and $\mathrm{FEV}_{1}$ values were also analysed as percentage of the predicted value in order to compensate for the confounding factors of sex, height and age. The variability in PEFR was also investigated on entry, towards the end of the trial nebuliser period, and close to discharge. For this analysis the difference between the lowest and highest PEFR values in a 24 hour period 
Table 3 Mean (SD) FEV, at the end of each treatment period

\begin{tabular}{|c|c|c|c|c|c|c|c|c|c|}
\hline \multirow[b]{2}{*}{ Group } & \multicolumn{3}{|l|}{12 hour FEV $V_{1}$} & \multicolumn{3}{|l|}{36 hour FEV $V_{1}$} & \multicolumn{3}{|l|}{60 hour FEV } \\
\hline & $\operatorname{PreS}$ & PostS & PostI & PreS & PostS & PostI/P & PreS & PostS & Post I/P \\
\hline I (1) & $1.61(0.87)$ & $1.79(0.94)$ & $1.84(0.95)$ & $1.75(0.78)$ & $2.05(0.80)$ & $2.13(0.88)$ & $1.88(0.74)$ & $2.13(0.72)$ & $2.21(0.71)$ \\
\hline (\%pred) & $48.5 \quad(18.5)$ & $53.5 \quad(19.4)$ & $55.5(20.6)$ & $54.9 \quad(19.5)$ & $64.8 \quad(20.4)$ & $66.9 \quad(21.0)$ & $60.8 \quad(20.2)$ & $69.9 \quad(20.9)$ & $71.7 \quad(20.6)$ \\
\hline II (1) & $1.64(0.96)$ & $1.88(1.03)$ & $1.96(1.05)$ & $2.01(1.02)$ & $2.27(1.16)$ & $2.30(1.18)$ & $2.05(1.13)$ & $2.26(1.17)$ & $2.31(1.15)$ \\
\hline (\%pred) & 47.1 & $53.9 \quad(24.0)$ & $56.4 \quad(23.9)$ & $57.2 \quad(22.7)$ & $64.3(25.2)$ & $65.5 \quad(26.4)$ & $57.5 \quad(25.7)$ & 63.0 & $65.1 \quad(25.3)$ \\
\hline III (1) & $1.96(0.82)$ & $2.18(0.82)$ & $2.20(0.86)$ & $2.21(0.71)$ & $2.43(0.76)$ & $2.43(0.77)$ & $2.18(0.57)$ & $2.48(0.73)$ & $2.54(0.66)$ \\
\hline (\%pred) & $57.0 \quad(24.3)$ & $63.8 \quad(24.5)$ & $64.5 \quad(23.9)$ & $64.3(21.2)$ & $70.0 \quad(20.8)$ & $70.4 \quad(21.2)$ & $63.3(16.2)$ & $71.2 \quad(19.1)$ & $73.6 \quad(17.6)$ \\
\hline
\end{tabular}

$\mathrm{S}=$ salbutamol; $\mathrm{I}=$ ipratropium bromide; $\mathrm{P}=$ placebo.

was determined as a percentage of the highest PEFR value for that period. The significance of differences in pulmonary function between groups was tested by analysis of variance (ANOVA). The duration of hospital stay for the three groups was compared using the Wilcoxon signed rank and Mann-Whitney U tests. The differences in symptom scores were analysed by ANOVA. A 5\% two tailed significance level was used, and the Bonferroni correction for multiple comparisons was applied. The randomisation code was broken only after completion of the study and computer entry of data.

\section{Results}

One hundred and six patients were entered into the study. The demographic characteristics are presented in table 1 . The groups were well matched for sex, age, entry PEFR, and symptoms on the first day of the study. Diurnal variability on entry was significantly less $(p \leqslant 0.017)$ for patients in group II $(19.8 \%)$ than for those in either group I $(29.4 \%)$ or group III $(29.1 \%)$.

Nineteen patients (five in group I, eight in group II, six in group III) withdrew prematurely and did not receive the three treatment limbs as intended. Premature withdrawal occurred for a variety of reasons, generally because recovery dictated transfer to an inhaler, or due to patient unwillingness to continue in the trial, rather than because of deterioration in clinical state.

The concomitant medication used to treat the acute attacks was similar for all groups (table 2). Small numbers of patients in each group received intravenous aminophylline and/or hydrocortisone, or antibiotics, but the

Table 4 Parameters of recovery

\begin{tabular}{lllll}
\hline Group & $\begin{array}{l}\text { Median (lower-upper } \\
\text { Q) duration of hospital } \\
\text { stay (days) }\end{array}$ & $\begin{array}{l}\text { Mean (SD) rate of } \\
\text { symptom change } \\
\text { (units/day) }\end{array}$ & $\begin{array}{l}\text { Mean (SD) time } \\
\text { to maximum } \\
\text { PEFR (hours) }\end{array}$ & $\begin{array}{l}\text { Mean (SD) diurnal } \\
\text { variability at end of } \\
\text { nebulisation (\%) }\end{array}$ \\
\hline I & $5.4^{\star}(3.7-7.6)$ & $6.5(3.8)$ & $77.8(65.2)$ & $23.6(17.2)$ \\
II & $4.1(3.0-5.7)$ & $6.6(4.6)$ & $64.1(46.3)$ & $16.5(8.8)$ \\
III & $4.0(3.1-5.1)$ & $8.0(4.0)$ & $52.4(33.9)$ & $16.2(12.2)$ \\
\hline
\end{tabular}

${ }^{\star}$ Group I vs group II, $\mathrm{p}=0.019$; group I vs group III, $\mathrm{p}=0.004$ (Wilcoxon signed rank test).

\#Symptom score: 0 = worst, $50=$ best.

Diurnal variability was calculated as: (best-worst PEFR)/best $\times 100$ within a 24 hour period. The duration of stay for group I was statistically significantly greater than for either group II or group III. $95 \%$ confidence intervals for differences between medians: group I-group II, 0.3 to 2.4 days; group I-group III, 0.5 to 2.5 days.

Table 5 Mean (SD) period differences in prebronchodilator PEFR

\begin{tabular}{llll}
\hline Group & $\begin{array}{l}\text { Change in PEFR during } \\
\text { period 1 (l/min) }\end{array}$ & $\begin{array}{l}\text { Change in PEFR during } \\
\text { period 2 (l/min) }\end{array}$ & $\begin{array}{l}\text { Change in PEFR during } \\
\text { period 3 (l/min) }\end{array}$ \\
\hline I & $85(68)$ & $27(62)$ & $12(56)$ \\
II & $86(81)$ & $53(73)$ & $5(47)$ \\
III & $90(100)$ & $50(69)$ & $16(42)$ \\
\hline
\end{tabular}

proportions of each group receiving such additional therapy did not differ significantly. Approximately one third of the patients in each group either carried on using nebulised treatment or reverted to this form of bronchodilator delivery once the trial had finished. The mean duration of treatment with nebulised salbutamol and ipratropium was slightly longer than specified for all groups, being 18 and 6 hours more for the two treatments, respectively, in the case of group I, 11 and 7 hours more for group II, and seven and five hours more for group III (table 2). The differences in salbutamol nebulisation times were not statistically significant.

Mean absolute and percentage predicted values of $\mathrm{FEV}_{1}$ at the end of each treatment period are presented in table 3 . There were no statistically significant differences between groups in any $\mathrm{FEV}_{1}, \mathrm{FVC}$, or peak flow values at any time point.

The median duration of hospital stay (table 4) was 5.4 days for patients in group I, 4.1 days for those in group II and 4.0 days for patients in group III, with the $95 \%$ confidence intervals for the differences being 0.3-2.4 days for groups I and II ( $\mathrm{p}=0.0125)$, and $0.5-2.5$ days for groups I and III ( $p=0.0028)$.

The behaviour of patients with very severe disease, defined as PEFR $<1501 / \mathrm{min}$ on entry to the study, was similar to that for the groups overall. Thus, severe patients from group I had significantly longer stays in hospital $(\mathrm{n}=12$, median 6.1 days) than did severe patients from either of the other two groups (group II: $\mathrm{n}=14$, median 4.4 days; group III: $\mathrm{n}=11$, median 4.5 days), but there was no difference between groups II and III.

The group differences in the rate of change of symptoms and the time to the greatest PEFR did not reach statistical significance but were consistent with the group differences in the times to discharge (table 4). Diurnal variability at the end of nebulisation showed greatest falls in group III, and the mean variability at this time for group I was significantly greater than for either of the other groups.

The diurnal variabilities in PEFR for the three groups were at similar levels and were below $15 \%$ at the time of discharge. In addition, mean discharge PEFR did not differ significantly between groups, being $407 \mathrm{l} / \mathrm{min}$ in group I, $397 \mathrm{l} / \mathrm{min}$ in group II, and $436 \mathrm{l} / \mathrm{min}$ in group III.

To determine a possible reason for the differences in the times to discharge, in the light of little difference in spirometric values, the changes in PEFR and $\mathrm{FEV}_{1}$ over the period of each treatment regimen were investigated. 
For PEFR the mean improvement seen over the second treatment period for groups II and III exceeded those for group I, although the differences did not reach statistical significance (table 5).

The progress of the patients after discharge was checked retrospectively from the hospital notes. Two patients in each group were readmitted to hospital or suffered a further exacerbation requiring a course of steroids before the next clinic visit (usually scheduled for 6-8 weeks from discharge).

\section{Discussion}

In this population of acute asthmatic patients those who received ipratropium bromide for 36 hours or more were discharged from hospital more rapidly than those who received the drug for only 12 hours.

On entry to the study the three groups were well matched in terms of demographic characteristics and two of the three indices of disease severity-PEFR levels and baseline symptom scores - were similar in the three groups. However, the diurnal variability at entry in group II was significantly lower than in the other two groups. This may have been related to the severity of the bronchoconstriction, a possibility supported by the slightly lower PEFR values on entry in group II, rather than indicating less severe asthma.

The responses to the nebulised agents at the end of each treatment period did not differ between groups. However, in contrast to groups II and III, the $\mathrm{FEV}_{1}$ values after ipratropium at the end of the first treatment period in patients in group I were slightly greater than those before salbutamol at the end of the second treatment period, perhaps indicating that patients in group I retained relatively marked variability. The $\mathrm{FEV}_{1}$ values for the other two groups showed a steady improvement from the value after nebulisation at the end of the first treatment period to the pretreatment value at the end of the second treatment period, implying that variability in airway calibre was declining faster in patients in groups II and III than in those in group I. The relative values for diurnal variability of PEFR at the end of the nebulised period would also support this possibility, as would the slightly shorter times to reach maximum PEFR in the patients in groups II and III.

The relative changes in prebronchodilator PEFR over the three treatment periods also support a less rapid recovery in group I than in the other two groups. All groups had improvements averaging $80-90 \mathrm{l} / \mathrm{min}$ in the first period, suggesting that the three populations were behaving similarly during the early recovery phase, as expected from the fact that all received ipratropium until this time (table 5). However, during the second treatment period, although the spirometric and PEFR responses to the drugs did not differ significantly between groups, the improvements in prebronchodilator PEFR were twice as large for the patients who continued on ipratropium (53 and $50 \mathrm{l} /$ min) than for those who were treated solely with salbutamol $(27 \mathrm{l} / \mathrm{min})$. The improvements in prebronchodilator PEFR achieved over the 24 hours of the third treatment period were considerably less than for the preceding period, with the mean increases in prebronchodilator PEFR for all groups amounting to $<17 \mathrm{l} / \mathrm{min}$.

The differences between groups in discharge times were not related to differences in concomitant medication as the proportions of patients who received additional therapy such as intravenous corticosteroids, antibiotics, intravenous aminophylline, and other bronchodilators were similar in the groups. In fact, patients in group I required longer than specified treatment with nebulised salbutamol, in keeping with a slower clinical recovery for this population compared with the other two groups. From analysis of diurnal variability it appears that patients in group I were not kept in hospital inappropriately. At the end of the nebulisation period these patients had significantly greater diurnal variation than those in the other two groups. However, this declined by the time of discharge by which time all three groups showed similar PEFR variability and similar discharge PEFR values, suggesting that patients from all groups were discharged at times appropriate to their clinical recovery. The faster discharge times of patients in groups II and III did not result in a greater number of subsequent readmissions or exacerbations than for group I, and therefore was not at the expense of inadequate control.

It would be expected that ipratropium with its relatively long duration of action would result in better bronchodilatation throughout the dosing interval than salbutamol alone. However, the group differences in PEFR and spirometric values did not reach statistical significance during the dosing period. Despite this, treatment with nebulised ipratropium resulted in a clear advantage in this study, and one which was measurable beyond the period of administration. This apparent anomaly may be partially explained by the fact that there is no single gold standard measure of asthma severity, and that clinicians interpret a collection of symptoms and signs when assessing the clinical state and progress of an asthmatic patient. Thus, in this study all three consultant chest physicians followed recommended practice by deciding on the readiness or otherwise of a patient for discharge on the basis of a variety of subjective and objective parameters. These include not only disease specific factors such as previous history, admission and change in symptoms, lung function and exercise tolerance, but also other considerations such as concomitant illness, social circumstances, and even the day of the week.

A further possible reason for the lack of group differences in spirometric values and PEFR is that the beneficial actions of bronchodilators in general, and ipratropium in particular, are not well assessed by standard lung function tests. These tests give no indication of the degree of air trapping and hyperinflation which both correlate with the severity of an attack and which may be reduced by bronchodilators. The relative FVC changes from the end of one treatment period to the next were also consistent 
with a slower rate of recovery in group I during the 12-36 hour period after entry.

The detailed responses to the trial drugs were not assessed beyond the end of the trial period. The percentage change in response to ipratropium over time appeared to vary inconsistently, and there was no evidence, as found by Teale et $a l,{ }^{9}$ that the relative amount of bronchodilatation provided by ipratropium increased as recovery progressed. Ipratropium was nebulised approximately 20 minutes after salbutamol so that the extent of bronchodilatation due solely to the second agent could not be determined from this study.

The results are consistent with those of most short term studies of nebulised ipratropium in acute adult asthma. Most have investigated single dosing or treatment for a maximum of 24 hours. Findings included enhanced bronchodilatation, ${ }^{2-6}$ increased duration of bronchodilatation, ${ }^{7}$ or faster bronchodilatation ${ }^{8}$ than with $\beta$ agonist alone. Three other studies have concluded that ipratropium adds nothing to the treatment of acute asthma. ${ }^{10-12}$ Two of these trials confined the parameter of recovery to PEFR measurements and investigated the effects for only two hours following the administration of salbutamol, with and without ipratropium, given early after the presentation to hospital. The third study used $\mathrm{FEV}_{1}$ recorded until 90 minutes after admission. There were significantly more responders to combination therapy at 45 minutes after presentation, but this advantage was not maintained. The current study is the first to monitor the impact of combined treatment with ipratropium and salbutamol over a prolonged period after admission, with the intention of attempting to define the optimum dosing period.

It is evident that treatment during the first 2.5 days after admission may have important effects on subsequent recovery, but that prediction of subsequent improvement is not possible from early spirometric and PEFR changes. However, we have found a definite advantage from the use of ipratropium for a period of approximately 36 hours after admission, but not beyond this. The increased costs of treatment with nebulised ipratropium over nebulised salbutamol alone are more than compensated for by the reduced length of hospital stay.

The authors wish to thank Professor Alan Silman, Dr Eric Gardner, Dr Jim Thompson, and Boehringer Ingelheim UK Ltd for their advice on analysis, and Dr Thompson and Dr Gardiner for performing analyses. We wish also to thank Boehringer Ingelheim UK Ltd for financial support in presenting the work.

1 British Thoracic Society, British Paediatric Association, Royal College of Physicians of London, King's Fund Centre, National Asthma Campaign, et al. Guidelines on the tre, National Asthma Campaign, et al. Guidelines
management of asthma. Thorax 1993;48:S1-24.

2 Ward MJ, Fentem PH, Roderick Smith WH, et al. Ipratropium bromide in acute asthma. BMF 1981;282: 598-600.

3 Bryant DH. Nebulized ipratropium bromide in the treatment of acute asthma. Chest 1985;88:24-9.

4 Rebuck AS, Chapman KR, Abboud R, et al. Nebulized anticholinergic and sympathomimetic treatment of asthma and chronic obstructive airways disease in the emergency room Am 7 Med 1987;82:59-63.

5 O'Driscoll BR, Taylor RJ, Horsley MG, et al. Nebulised O'Driscoll BR, Taylor RJ, Horsley MG, et al. Nebulised
salbutamol with and without ipratropium bromide in acute airflow obstruction. Lancet 1989;ii:1418-20.

6 Bryant DH, Rogers P. Effects of ipratropium bromide nebulizer solution with and without preservatives in the treatment of acute and stable asthma. Chest 1992;102:742-7.

7 Higgins RM, Stradling JR, Lane DJ. Should ipratropium bromide be added to beta-agonists in treatment of acute severe asthma. Chest 1988;94:718-22.

8 Louw SJ, Goldin JG, Isaacs S. Relative efficacy of nebulised ipratropium bromide and fenoterol in acute severe asthma. $S$ Afr Med F 1990;77:24-6.

9 Teale C, Morrison JFJ, Muers MF, et al. Response to nebulized ipratropium bromide and terbutaline in acute severe asthma. Respir Med 1992;86:215-8

10 Leahy BC, Gomm SA, Allen SC. Comparison of nebulized salbutamol with nebulized ipratropium bromide in acute asthma. Br F Dis Chest 1983;77:159-63.

11 Summers QA, Tarala RA. Nebulized ipratropium in the treatment of acute asthma. Chest 1990;97:430-4.

12 Karpel JP, Schacter EN, Fanta C, et al. A comparison of ipratropium and albuterol vs albuterol alone for the treatment of acute asthma. Chest 1996;110:611-6. 